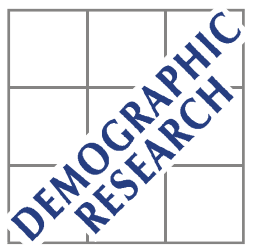

Demographic Research a free, expedited, online journal of peer-reviewed research and commentary in the population sciences published by the Max Planck Institute for Demographic Research Konrad-Zuse Str. 1, D-18057 Rostock · GERMANY www.demographic-research.org

DEMOGRAPHIC RESEARCH

VOLUME 25, ARTICLE 26, PAGES 819-836

PUBLISHED 9 DECEMBER 2011

http://www.demographic-research.org/Volumes/Vol25/26/

DOI: 10.4054/DemRes.2011.25.26

Research Article

\title{
China's far below-replacement fertility and its long-term impact: Comments on the preliminary results of the 2010 census
}

\section{Zhongwei Zhao}

\section{Wei Chen}

(C) 2011 Zhongwei Zhao \& Wei Chen.

This open-access work is published under the terms of the Creative Commons Attribution NonCommercial License 2.0 Germany, which permits use, reproduction \& distribution in any medium for non-commercial purposes, provided the original author(s) and source are given credit.

See http:// creativecommons.org/licenses/by-nc/2.0/de/ 


\section{Table of Contents}

$\begin{array}{lll}1 & \text { Introduction } & 820\end{array}$

2 China's fertility has been well below replacement level: New evidence from the 2010 census

3 Is there evidence suggesting that China's recent fertility has been much higher than that indicated by the 2010 census results?

$4 \quad$ What would be the major impacts of China's recent far belowreplacement fertility?

$5 \quad$ Has our understanding of the current fertility situation, policy responses, and development plans fallen behind China's demographic changes?

Concluding remarks

830

7 Acknowledgement

832

References 


\title{
China's far below-replacement fertility and its long-term impact: Comments on the preliminary results of the 2010 census
}

\author{
Zhongwei Zhao ${ }^{1}$ \\ Wei Chen ${ }^{2}$
}

\begin{abstract}
The Chinese government conducted its sixth national census in 2010 and released its major results in April 2011. According to the National Bureau of Statistics the quality of the census was very high. Although the currently released census results consist of limited statistics only, they shed new light on China's recent fertility levels, which have been debated among scholars and policy makers for more than a decade. The 2010 census results, however, also show considerable inconsistencies with those published by the United Nations Population Division recently. This paper will, on the basis of newly published census results and other available evidence, further examine China's recent fertility decline and its impact on the country's long-term development. It will also comment on the major discrepancies between the results of Chinese government recent population projection, the United Nations' World Population Prospects, the 2010 Revision and China's 2010 census, and investigate the underlying causes that have led to these differences.
\end{abstract}

\footnotetext{
${ }^{1}$ Australian National University. E-mail: zhongwei.zhao@anu.edu.au.

${ }^{2}$ People's University, China. E-mail: weichen@ruc.edu.cn.
} 


\section{Introduction}

The Chinese government conducted its sixth national census in 2010 and released its major results in April 2011. According to the National Bureau of Statistics (NBS) the quality of the census was very high and its net under-enumeration rate was only $0.12 \%$, which is significantly better than the $1.81 \%$ recorded in the fifth census carried out in 2000 (NBS 2011a). This under-enumeration rate is also much lower than those observed in recent censuses undertaken in Australia, Canada, New Zealand, the UK, and the USA, most of which were between 1.5\% and 3\% (Abbott 2008; Australian Bureau of Statistics 2003; British Columbia Statistics 2003; Groves 2010; Statistics New Zealand 2011).

Although the currently released census results consist of limited statistics only, they shed new light on China's recent fertility levels, which have been debated among scholars and policy makers since the publication of the 2000 census results some ten years ago. However, the census results have shown notable inconsistencies with those obtained from some other demographic data sources. In this paper we will investigate the major discrepancies between the results of Chinese government recent population projection, the United Nations' World Population Prospects, the 2010 Revision and China's 2010 census, and comment on our current understanding of China's recent fertility changes. Based on the newly published census results and other available evidence, we will also examine China's continuous fertility decline and its impact on the country's future sustainable development.

\section{China's fertility has been well below replacement level: New evidence from the 2010 census}

In the newly released census results China's national population has been divided into three broad age groups. In Table 1 the number of people in these age groups is listed in the upper panel and its percentage distribution in the lower panel of column 5. The table presents similar statistics from other data sources for comparison. Figures in column 4 are obtained from World Population Prospects, the 2010 Revision, published by the United Nations (UN), which is also called as the UN 2010 Population Projections. The percentage distributions in column 3 were recorded by the 2009 Annual Population Change Sample Survey conducted by the NBS. ${ }^{3}$ The population numbers have been

\footnotetext{
${ }^{3}$ The Chinese government did not conduct an annual population change survey in 2010 . The reported population figures for that year were estimated from, and are therefore very close to, the census results. Because of this they are not presented in the table.
} 
calculated directly by the authors using the sample ratio (the proportion of the sampled population in the national population), sample size, and the age distribution of the sampled population, which is based on the assumption that sample ratios were the same in all three age groups. ${ }^{4}$

Table 1: Distribution of the Chinese population by broad age groups

\begin{tabular}{lcccc}
\hline & Age group & $\mathbf{2 0 0 9}$ & $\mathbf{2 0 1 0}$ & $\mathbf{2 0 1 0}$ \\
\hline Population (in millions) & & & & \\
& $0-14$ & 225 & 261 & 222 \\
& $15-59$ & 916 & 915 & 940 \\
& $60+$ & 193 & 165 & 178 \\
Proportion (\%) & Total & 1335 & 1341 & 1340 \\
& & & & \\
& $0-14$ & 16.9 & 19.5 & 16.6 \\
& $15-59$ & 68.6 & 68.2 & 70.1 \\
Data sources & $60+$ & 14.5 & 12.3 & 13.3 \\
\hline
\end{tabular}

Sources: NBS (2010); NBS (2011a); UN (2011).

According to the census, the number of people aged 15-59 was 940 million in 2010. This figure is reasonably close to the 915 million obtained from the UN 2010 population projections and consistent with the 916 million estimated from China's annual population change survey data for 2009 (NBS 2011a; UN 2011). ${ }^{5}$ The census result is about 24 million, or nearly $3 \%$, greater than the other two figures. ${ }^{6}$ According to the 2010 census, the number of people aged 60 and over was 178 million. This is about 13 million, or more than $7 \%$, greater than the 165 million estimated by the UN

\footnotetext{
${ }^{4}$ Ideally, we would like to use sample ratios by age groups, but such information is not available.

${ }^{5}$ We can only use annual population change survey data to estimate the figure for 2009 , because similar data are not available for 2010 .

${ }^{6}$ In this and other places, the following formula is used to compare the difference between population figures obtained from different data sources: Percentage difference $=($ results of 2010 census - results from other data sources $) \div$ results of 2010 census. That the number of people aged 15-59 estimated from the 2009 annual population change survey is smaller than that recorded by the 2010 census may be partly explained by the annual survey under-recording young people in this age group, because they were more likely to be migrants and be missed out in the enumeration. But the census made considerable effort to reduce such impacts. In the 2010 census, migrants are enumerated in both their home town (i.e., where their household registration was kept) and where they lived.
} 
2010 population projections, while it is 15 million, or approximately $8 \%$, smaller than the estimated 193 million from the annual population survey results for $2009{ }^{7}$

China's 2010 census recorded 222 million children aged 0-14, which is consistent with the 225 million estimated for 2009 from the annual population survey data. However, the census result is markedly lower than the 261 million estimated by the UN 2010 population projections. The difference between them is more than 38 million, or the census result is about $18 \%$ smaller.

This large difference leads to a number of questions. If the under-enumeration rate of children aged 0-14 in the 2010 census was indeed very low or close to the overall under-enumeration rate reported by the NBS, what kind of fertility level does the census result imply? As indicated by the above discussion, the number of women of reproductive age obtained from the UN 2010 population projections is reasonably close to that recorded by China's 2010 census. Accordingly, the major difference in the numbers of $0-14$ year olds is most likely to have been caused by the gap in the fertility levels of the two populations. In the UN population projections the average Total Fertility Rates (TFRs) for the periods 1995-2000, 2000-2005, and 2005-2010 were 1.80, 1.70 , and 1.64, respectively (UN 2011). If the number of those aged 0-14 were recorded accurately by the 2010 census, China's actual TFRs must be considerably lower than those suggested by the UN Population Division for the years 1995 to 2010 (or the UN Population Division has significantly over-estimated the number of children in this age group). Because the census-recorded number of women aged 15-49 was very likely to be larger than that estimated by the UN Population Division, it could lower the fertility rate further.

Then how low could China's recent fertility have been if the census-recorded number of children were accurate? To answer this question we have carried out the following exercise. We first selected and determined the population in 1990, which had the same size and age and sex structure as that used in the UN 2010 population projections. This has been used as our starting population. We then selected age patterns of fertility and age-specific mortality rates that are in general also very similar to those used in the UN population projections. In this exercise we did not consider the influence of international migration, because its impact on China's short-term

\footnotetext{
${ }^{7}$ A possible explanation for the difference in the number of people aged 60 and over between the census result and that estimated from the 2009 annual population change survey results could be that, at the time of the annual survey, household registration of some deceased people (who were most likely to have died at old ages) were not cancelled after their death. Hence, they might still have been recorded in the survey. However, the Chinese government systematically updated household registration before the census. This greatly improved the quality of household registers and contributed to the reduction in the recorded number of people aged 60 and over in the 2010 census. As for the difference between the UN population projection result and the census result, it is very likely to be related to the difference in mortality estimated by the UN Population Division and recorded by the 2010 census. While the level of census-recorded mortality could be affected by enumeration problems, we have not been able to examine this due to data availability.
} 
population changes is very small. The major difference between the UN 2010 population projection and ours is that we have lowered fertility levels from 1.80 to 1.60 for 1995-2000, from 1.70 to 1.45 for 2000-2005, and from 1.64 to 1.45 for 2005-2010. Because of this our projection, in comparison with that made by the UN Population Division, is expected to produce a population in which the number of those aged 0-14 is closer to that recorded by the 2010 census. We have used this method to estimate the population for the last two decades and to project it into the future. According to this projection, the number of children aged 0-14 will be 229 million by the end of 2010, which is still several million larger than the figure reported by the census. This suggests that, if the census records were accurate, the average TFR would be lower than 1.60 for 1995-2000 and lower than 1.45 for the past 10 years. They are all considerably lower than the 1.8 reported by the Chinese government in recent years.

The above comparison leads to the following conclusions. The number and proportion of 0-14 year olds recorded by the 2010 census are highly consistent with those estimated for 2009 from the annual population change survey data. They are also very consistent with the declining trend of those aged $0-14$, which was discovered by the annual population change surveys conducted in the past 15 years (Zhao 2011), although they are markedly smaller than those estimated by the UN 2010 population projections. These results show that if the 2010 census indeed accurately enumerated those aged 0-14, the average TFR for 1996-2010 would be significantly lower than the 1.8 reported by the Chinese government, and for the last decade the TFR was very likely to have been lower than 1.45 .

\section{Is there evidence suggesting that China's recent fertility has been much higher than that indicated by the 2010 census results?}

While the suggestion made in the last section is very plausible, it is not conclusive and therefore requires further investigation. As Table 1 shows, if the 2010 census records of 0-14 year olds were of high quality the UN 2010 population projections would have over-estimated the number of children of these ages by more than 38 million, indicating an over-estimation of China's fertility for the past 15 years. Otherwise, China's actual fertility would have been much higher than that suggested by the 2010 census results.

Assuming that the census data were accurate, how did the UN Population Division considerably over-estimate China's recent fertility? This is likely to have resulted from the UN Population Division's practice, when estimating and projecting population, of 
relying heavily on the demographic data provided by member countries. ${ }^{8}$ Then is there evidence suggesting that the Chinese government has over-reported its fertility, which might have been used as the basis for the UN population projections? The answer is yes.

As indicated by the discussion in the last section and that presented below. The number of people aged 0-14 recorded by the 2010 census ought to be consistent with the number of births reported by the NBS in the previous 15 years, if both of them are accurate. According to the NBS about 258 million births were recorded over the period from 1996 to 2010. If we assume that on average 3\% of them died before the end of 2010, then the number of those aged 0-14 and still alive would be about 251 million. If this estimated result were correct or very close to the actual number, the 2010 census would have under-counted around 28 million children aged 0-14. Although this number is about 10 million smaller than the gap of 38 million that is indicated by the UN 2010 population projections, the question is whether there is evidence to support an underenumeration of this magnitude.

As mentioned earlier, the net under-enumeration rate was only $0.12 \%$ in the 2010 census, according to the Chinese government (NBS 2011a). If the large difference between the number of the census-recorded 0-14 year olds and that indicated by the officially reported number of children born in the previous 15 years were the result of under-enumeration, then the under-enumeration rate of children aged $0-14$ in the census would be more than $11 \%$. It is very unlikely that the net under-enumeration rate was so low in other age groups and so high among those aged 0-14- more than 90 times worse than that for the total population. Furthermore, the officially reported underenumeration rate also indicates that only about 1.6 million people were under-counted in the entire population. This means that if the gap of 28 million in the number of $0-14$ year olds all resulted from under-enumeration, then more than 26 million people aged 15 and above must have been double counted in the census. According to Ma JianTang, the director of the NBS, this is also unlikely, because double counting of this kind was systematically checked and corrected before the census results were published (Ma 2011).

It is important to point out that fertility data released by the Chinese government (or different government departments) have been inconsistent in the last 15 years (Gu and Cai 2009; Zhao and Zhang 2010). While fertility data reported by the National Population and Family Planning Commission and those endorsed by the State Council (which are often adjusted figures) have consistently shown a higher fertility, fertility

\footnotetext{
${ }^{8}$ As indicated by some studies (Cai 2011; Zhao 2011), in conducting its 2010 population projection for China the UN Population Division notably revised the fertility input parameters that it had used in the 2008 population projection, which led to considerable differences in their results. But these revised fertility rates were still much higher than those suggested by many researchers.
} 
levels revealed by unadjusted annual population change survey and fertility survey results have been much lower. ${ }^{9}$ There is considerable evidence suggesting that China's fertility level has been over-inflated in recent years by the officially endorsed fertility statistics. For example, in the last 15 years all but one of the annual population change surveys and fertility surveys have recorded a consistently low fertility. While the 2006 National Population and Family Planning Survey reported higher TFRs for 2005 and 2006 , they were subsequently found to have resulted from problems in sample selection (Zhao and Guo 2010; Zhao and Zhang 2010). These suggestions are further supported by a recent study which revealed that government-reported numbers of children aged 0 14 were on average $7 \%$ greater than those calculated directly from the annual population sample survey results over the period 1996-2009 (Zhao 2011).

In the last decade many studies have been undertaken investigating China's recent fertility levels, and they have found that the number of births has been over-reported by the Chinese government for more than ten years (Qiao 2005; Zhang and Zhao 2006; Zhao and Zhang 2010). These studies have also provided consistent evidence showing that China's TFR declined steadily from above replacement in 1990 to lower than 1.6 in 2000. In the first decade of the 21 st century it fell further and fluctuated around an even lower level (Cai 2008, 2010; Guo and Chen 2007; Retherford et al. 2005; Scharping 2005; Zhao and Guo 2010).

\section{What would be the major impacts of China's recent far below-replacement fertility?}

According to the evidence presented in the last two sections, China's recent fertility levels are likely to have been significantly lower than those claimed by the government, and those estimated by the UN Population Division for the periods 1995-2000, 20002005, and 2005-2010, published in World Population Prospects, the 2010 Revision. Therefore the population projection results reported by either the Chinese government or the UN Population Division may not accurately represent China's actual demographic situation, and thus might not provide a reliable basis for developing longterm socio-economic plans for the country.

To illustrate their impacts we have extended our simple population projection, discussed in section one, to 2050 . We have conducted a population projection that is in most respects very similar to the UN 2010 population projection for China, but we have lowered the fertility levels for $1995-2000$ from 1.80 to 1.60 , for $2000-2005$ from 1.70 to

\footnotetext{
${ }^{9}$ These results have often been published quietly and are regarded as affected by under-enumeration problems.
} 
1.45 , and for 2005-2010 from 1.64 to 1.45 . Because of this the number of $0-14$ year olds produced by our projection is reasonably close to that recorded by the 2010 census. For the period 2010-2050 we have used the same TFRs published in World Population Prospects: the 2010 Revision by the UN Population Division, which vary between 1.51 and 1.58 in years 2010-2030, and increase from 1.63 to 1.77 in years 2030-2050. We are aware that the fertility change made by us leads to an increase in TFR from 2010 to 2011, and that it may be questionable if this is a realistic scenario. However, these rates are used in the exercise because one of its major objectives is to examine the impact of over-estimating fertility for 1995 to 2010.

By prolonging the population projection to 2050 the results should shed light on the long-term impact of the lowered fertility on China's future demographic changes. The comparison of the UN Population Division projection results and our projection results is shown in Table 2. Since most of their input parameters other than fertility rates for 1995-2010 are very similar, the major discrepancies between the two sets of projection results are caused largely by the different fertility parameters. We would like to compare the results produced by the population projection of the Chinese government in a similar way, but its detailed information and results are not available. ${ }^{10}$

The following observations can be made from the comparison of the abovementioned population projection results and those reported by the Chinese government. The General Report on China's National Strategy on Population Development, published in 2007, predicted a 2010 national population of around 1.35 billion. The general report also suggests that the national population will continue to grow and reach a peak of around 1.5 billion in 2033. After that it will start to decline, but China's total population might still be more than 1.4 billion in 2050. China's working age (15-64) population will reach a peak of 1.01 billion in 2016. Then it will fluctuate around 1 billion for more than a decade before starting a long-term and rapid decline in the late 2020s. By 2050 China's working age population will be about 880 million. China's elderly population (those aged 65 and over) will reach $11.2 \%$ of the national population in 2020 and further increase to 22\% in late 2040 (National Strategy on Population Development Research Group 2007).

The results of the UN 2010 population projections differ markedly in several aspects from those projected by the Chinese government. According to the UN population projections, China's total population will reach its peak of less than 1.4 billion in 2026. It will be about 1.38 billion in 2033 and less than 1.3 billion in 2050, much smaller than those projected by the Chinese government. China's working age

\footnotetext{
${ }^{10}$ While The General Report on China's National Strategy on Population Development mentioned some of the government-projected results, it did not provide detailed projection results like those published by the UN Population Division. Z. Guo has kindly showed us his population projections results. Among these results those produced by projection scenario 13 are very similar to those discussed in the general report, although there are also some differences.
} 
(15-64) population will also peak in 2016 at 996 million, or slightly lower than that projected by Chinese government. However, it will be less than 800 million in 2050, which is 90 million less than that reported by the Chinese government. As for the proportion of those aged 65 and over, the UN population projections show that it will be $12 \%$ in 2020 , or slightly higher than that suggested by the Chinese government. But it will increase at a greater speed and reach about $26 \%$ in 2050 . The old age dependency ratio will increase from currently less than 12 old people per 100 working-age population to 42 old people per 100 working-age population in the mid-21st century (United Nations 2011).

Table 2: Population projection results made by the United Nations population division and ourselves

\begin{tabular}{lcccccc}
\hline & \multicolumn{2}{c}{$\begin{array}{c}\text { Total Population } \\
\text { (millions) }\end{array}$} & \multicolumn{2}{c}{$\begin{array}{c}\text { Population aged 15-64 } \\
\text { (millions) }\end{array}$} & \multicolumn{2}{c}{$\begin{array}{c}\text { Proportion aged 65+ } \\
\text { (\%) }\end{array}$} \\
Year & $\begin{array}{c}\text { UN 2010 } \\
\text { projection }\end{array}$ & $\begin{array}{c}\text { Authors' } \\
\text { projection }\end{array}$ & $\begin{array}{c}\text { UN 2010 } \\
\text { projection }\end{array}$ & $\begin{array}{c}\text { Authors' } \\
\text { projection }\end{array}$ & $\begin{array}{c}\text { UN 2010 } \\
\text { projection }\end{array}$ & $\begin{array}{c}\text { Authors' } \\
\text { projection }\end{array}$ \\
\hline 2010 & 1,341 & 1,309 & 971 & 971 & 8.2 & 8.4 \\
2015 & 1,370 & 1,338 & 996 & 985 & 9.5 & 9.7 \\
2020 & 1,388 & 1,354 & 989 & 966 & 12.0 & 12.3 \\
2025 & 1,395 & 1,358 & 981 & 949 & 14.0 & 14.4 \\
2030 & 1,393 & 1,350 & 960 & 928 & 16.5 & 17.0 \\
2035 & 1,382 & 1,333 & 910 & 877 & 20.2 & 21.0 \\
2040 & 1,361 & 1,309 & 859 & 822 & 23.3 & 24.2 \\
2045 & 1,332 & 1,277 & 829 & 786 & 24.4 & 25.3 \\
2050 & 1,296 & 1,238 & 790 & 742 & 25.6 & 26.8 \\
\hline
\end{tabular}

Sources: UN (2011), the projection made by the authors.

Because our projection has used lower fertility rates for 1995 to 2010 in comparison with those used in the UN population projections, the difference between our projection results and those reported by the UN Population Division are obvious. While our projected total population and working-age population will reach their peaks at about the same time as that suggested by the UN population projections, their size will be markedly smaller. According to our projection the Chinese population will reach 1.36 billion in 2025, approximately 1.34 billion in 2033, and 1.24 billion in 2050 . The working-age population will be about 985 million in 2016 and 742 million in 2050. The proportion of people aged 65 and over will be more than $12 \%$ in 2020 and reach $27 \%$ in 2050. Our projected old-age dependency ratios are also higher than those projected by the UN Population Division. 
In comparison with those projected by the Chinese government, our projected national population will be around 150 million less in 2033 and nearly 200 million less in 2050. Our projected working-age population will be about 15 million less in 2016, but the gap will increase to approximately 140 million in 2050. Our projected proportion of people aged 65 and over will be about $5 \%$ greater in the middle of the 21 st century. Differences of such a magnitude will have significant impacts on the formation of China's future development plans and strategies, which in turn will greatly affect the long-term development and future of the country.

\section{Has our understanding of the current fertility situation, policy responses, and development plans fallen behind China's demographic changes?}

If China's fertility has indeed been very low, and the population projection results reported by both Chinese government and the UN Population Division have underestimated this change and its impacts, why and how could this have happened?

Historically, it is not uncommon for social changes to take place faster than expected. One example is the extraordinary fertility decline of recent decades: a few decades ago few demographers thought that fertility could fall to and stay at far below replacement levels, but in many places this has now become reality. Even in some countries that had very high fertility some 40 years ago, TFRs are now well below replacement. In an article published in 1986 a well-known demographer Ronald Freedman acknowledged that he had underestimated the rate of fertility decline in Taiwan. He used this admission as an example to convince readers that "social scientists, including demographers, have consistently underestimated the rate at which social change can occur" (Freedman 1986:529). It is clear that our thinking and some policies have also considerably lagged behind the rapid fertility changes that have been taking place in mainland China.

This is indicated by the fact that, for quite a long time, researchers (including ourselves) and policy makers did not believe that China's fertility fell sharply in the early 1990s and declined further thereafter. Partly for this reason they tended to accept the suggestion that under-recording of births in some demographic surveys and population data was far more severe than what was actually observed. This led to a tendency to over-adjust certain fertility statistics. It is interesting to note that while China's recent annual population change survey and fertility survey results have consistently shown a fertility far below replacement level, these results have been barely mentioned in official documents on China's fertility and population changes. Some demographers started questioning these notions and practices in the first half of 
the last decade, and several studies have been undertaken since (Cai 2008, 2010; Gu and Cai 2009; Qiao 2005; Retherford et al. 2005; Scharping 2005; Zhang and Zhao 2006; Zhao and Guo2010; Zhao and Zhang 2010). This has gradually changed their views about China's continuing fertility decline after it fell below replacement in the early 1990s. However, changes of this kind have not yet been observed among policy makers.

Many policy makers and some scholars are not convinced that China's fertility has been well below replacement level because they do not believe that profound changes have already taken place in the reproductive culture in Chinese society. It is interesting that in the discussion of economic development they were very confident that mainland China, just like Asia's four small dragons (Hong Kong, Singapore, South Korea, and Taiwan), could achieve and maintain rapid economic growth, which has been proven correct. However, when addressing fertility decline these policy makers and scholars have been far less confident in suggesting that in Mainland China fertility reduction may also be similar to that experienced by its four small counterparts. Many people still consider that China's current low fertility is largely a result of strict birth control imposed by the family planning program, rather than the outcome of a secular change in people's fertility preferences. Following this reasoning they insist that China's family planning policy must be upheld and every effort should be made to implement the government-led family planning program and that this remains a key step in implementing China's National Strategy on Population Development (National Strategy on Population Development Research Group 2007).

Although these views may not be entirely wrong, and family planning does still face difficulties in certain areas, it is important to acknowledge the significant change in reproductive culture since the early 1970s. After forty years of family planning and three decades of rapid socio-economic development, the small family has already been accepted as the reproductive norm by the majority of young people, who themselves have grown up in this new environment and have been subject to increasing international influences. Their ideal number of children has been falling, as shown by many surveys. There are also signs that son preference has been weakening among young people. ${ }^{11}$ According to the National Population and Family Planning Commission (NPFPC), China's family planning rate (percentage of births having

\footnotetext{
${ }^{11}$ For example, a recent survey showed that the average ideal number of children was 1.74 among 1,700 migrants from central and west China, and 1.58 for unmarried young migrants (Floating Population Research Group 2010). Another survey reported that the average ideal number of children was 1.72 among 1,300 married women surveyed in three provinces of China. The survey also found weakening son preference in the study population: $56 \%$ stated that they preferred to have an equal number of sons and daughters, while $23 \%$ wanted more sons than daughters, and $21 \%$ wanted more daughters than sons. The percentage wanting more sons was still higher than that wanting more daughters across all age groups, but their difference is narrowing. The proportion of women who hoped to have an equal number of sons and daughters has risen from $46 \%$ for those aged over 35 to $64 \%$ for those aged under 30 (Sex Ratio at Birth Research Group 2010).
} 
satisfied government birth control plans) has stabilized at the high level of $93 \%$ in recent years (NPFPC 2008). Running the family planning program has become much easier than before. Even in areas where each family has been allowed to have two children many couples have chosen to have one child, and the TFR has been below two children per woman. In most of these places relaxed family planning policies have not resulted in higher fertility in comparison to neighboring regions with stricter family planning policies (Cai 2010; Gu and Wang 2009; Zheng et al. 2009). All these are important indications that the major driving force of China's current low fertility is no longer the strict birth control imposed by the government. It is worth mentioning that in Taiwan the TFR has not recuperated since it fell below replacement in 1984, but declined to a very low level in the last quarter of the 20th century. A similar change has been taking place in mainland China. This is part of profound social, demographic, and cultural changes that have been observed in many countries in the world. Even if the Chinese government relaxed its family planning policies it is very unlikely that China's fertility would bounce back to and stay around the replacement level in the near future.

Because of the notable lag between our thinking and the rapid socio-demographic changes, it is not surprising that some population projections and development plans have also fallen behind these changes. For example, The General Report on China's National Strategy on Population Development insists that China will maintain its TFR at the level of 1.8 over the next 30 years. But it does not even discuss the possibility that fertility could fall below this level and, if it happens, how the much lower fertility could be lifted to this desired level, despite a considerable amount of evidence showing that such low fertility has already existed for more than a decade (National Strategy on Population Development Research Group 2007). Similarly, China's recent fertility reduction and its long-term impact have been notably under-estimated by the population projections made by both the Chinese government and the UN Population Division, as shown earlier. These projections may not provide reliable demographic information for developing China's long-term socio-economic plan, which will be very important for its future sustainable development.

\section{Concluding remarks}

The evidence presented in this paper shows that in recent years China's officially endorsed fertility statistics seemed to have resulted from the politics of numbers rather than reflecting China's demographic reality. For some policy makers the most important grounds on which to base their decision about China's fertility levels are no longer the results of various fertility-related surveys and research findings made through detailed investigation, but other considerations. 
There has been plenty of evidence showing that in the last 15 years the difficulty of promoting family planning has greatly reduced and the recorded fertility has been notably lower than 1.8 (Cai 2010; Gu et al. 2007; Gu and Cai 2009; Goodkind 2011; Retherford et al. 2005; Zhang and Zhao 2006; Zhao and Guo 2010; Zheng et al. 2009). However, the Chinese government has maintained that China's TFR has been around 1.8. Why has the government been particularly favorable to this number in reporting its fertility level? The selection of 1.8 seems not to be arbitrary or anecdotal, but to be related to the following characteristics of this figure: a TFR of 1.8 is below, but not too far from, replacement fertility. This fertility level would gradually reduce China's population size, while not seriously upset its age structure, as would be the case with a much lower fertility level. It is also higher, but not markedly higher, than the policy fertility level established by the government. Therefore it can easily accommodate the argument that the family planning program has been significantly successful but still faces considerable challenges in implementing the government fertility policy. Accordingly, family planning work should be both awarded for its achievements and given further support because of its difficulties.

The evidence presented in this paper and elsewhere suggests that for more than 15 years China's fertility has been notably lower than that reported by the government. It is also lower than that recently published in the World Population Prospects, the 2010 Revision. If this is indeed the case, now is a good time for the NBS to update the population statistics published by the Chinese government in recent years. Similarly, if there is sufficient evidence showing that the UN 2010 population projection results have noticeably misrepresented China's current demographic situation, the UN Population Division has a responsibility to revise its results.

We have noted the large discrepancy in the number of people aged 0-14 when comparing China's 2010 population figures and the UN 2010 population projections. Despite the significant gap, the total population of China projected by the UN Population Division is remarkably close to that reported by the Chinese government (UN 2011, NBS 2011b). As expected, the UN Population Division's projections for the 15-64 and 65+ age groups are both noticeably smaller than those reported by the Chinese government. This leads to another intriguing and perhaps more complicated question: what has caused these differences (especially when the UN projection for the number of children is considerably larger than the figure reported by the Chinese government)? We are not able to complete the investigation of this question, because it requires detailed data on population by smaller age groups and information on recent mortality, especially old age mortality, which are not yet available.

In this commentary we have reached several conclusions concerning China's recent fertility levels. We are aware of the uncertainty of some of these conclusions and suggestions, partly arising from our assumption that the quality of China's 2010 census 
was high, as claimed by the Chinese authorities. Similarly, we are aware of that the enumeration problems in the 2010 census can be far more complex than those reported by the NBS. Under-recording is very likely to have been distributed unevenly among major age groups. Double counting or over-counting of other kinds may still exist. The under-enumeration rate may be higher than that reported by the Chinese government. All these could impact on the conclusions drawn in this paper. We are interested in further examining these possibilities and their impacts, but this cannot be done because of the constraint imposed by data availability.

The remarkable differences among major demographic data sources concerning China's recently reported fertility levels and projected future population changes underscore the urgent need to further investigate these inconsistencies and their significant impacts on the formation of China's future development plans and strategies. To clear the confusion and misunderstanding about China's current demographic situation, which could profoundly influence the country's long-term demographic changes and sustainable development, great efforts must be made to further improve the collection and publication of China's demographic data and other statistics. In addition to necessary methodological and technological advancements, these efforts include increasing the transparency of data collection, adjustment, and publication, improving people's right to know, and strengthening the legal protection of China's statistics and the rights of statistical establishments.

\section{Acknowledgement}

The authors would like to acknowledge the partial support provided by Australian Government ARC research grant (DP1096696), China National Social Science Fund (Grant No. 09BRK003) and Australian Centre on China in the World at the Australian National University. 


\section{References}

Abbott, O. (2008). 2011 UK census coverage assessment and adjustment methodology. Proceedings of Q2008 European Conference on Quality in Official Statistics.http://q2008.istat.it/sessions/paper/06Abbott.pdf (July 2011).

Australian Bureau of Statistics (2003).Census update (News letter). http://www.abs.gov.au/ausstats/abs@.nsf/7d12b0f6763c78caca257061001cc588/ 0382f7854d89fcc8ca2573220016f312!OpenDocument (July 2011).

British Columbia Statistics, Population Section (2003). Feature article: How many people were missed in the 2001 Census? Population Section, BC STATS, Ministry of Management Services. http://www.bcstats.gov.bc.ca/pubs/mig/ mig032fa.pdf (July 2011).

Cai, Y. (2008). An assessment of China's fertility level using the variable- $r$ method. Demography 45(2): 271-281. doi:10.1353/dem.0.0003.

Cai, Y. (2010). China's below replacement fertility: Government policy or socioeconomic development. Population and Development Review 36(3): 419440. doi:10.1111/j.1728-4457.2010.00341.x.

Cai, Y. (2011). United Nations Population Projection still overestimated China's fertility level. First Caijing Daily (23 May 2011). http://big5.xinhuanet.com/ gate/big5/www.cnstock.com/index/gdbb/201105/1317694.htm (September 2011, in Chinese).

Floating Population Research Group (2010). China Floating Population Research, unpublished report. Center for Population and Development Studies, People's University of China.

Freedman, R. (1986). On underestimating the rate of social change: A cautionary note. Population and Development Review 12(3): 529-532. doi:10.2307/1973222.

Goodkind, D. (2011). Child underreporting, fertility, and sex ratios imbalance in China. Demography 48(1): 291-316. doi:10.1007/s13524-010-0007-y.

Groves, R.M. (2010). Director's blog: Quality in a census, some overview thoughts. $\mathrm{http}$ //blogs.census.gov/directorsblog/2010/09/quality-in-a-census-someoverview-thoughts.html (July 2011).

Gu, B. and Cai, Y. (2009). Fertility prospects in China. Paper presented at the United Nations expert group meeting on recent and future trends in fertility, New York, December 2009. 
Gu, B. and Wang, F. (eds.) (2009). An Experiment of Eight Million People. Beijing: Social Sciences Academic Press (in Chinese).

Gu, B., Wang, F., Guo, Z., and Zhang, E. (2007). China's local and national fertility policies at the end of the twentieth century. Population and Development Review 33(1): 129-148. doi:10.1111/j.1728-4457.2007.00161.x.

Guo, Z. and Chen, W. (2007). Below replacement fertility in Mainland China. In: Zhao, Z. and Guo, F. (eds.). Transition and Challenge: China's Population at the Beginning of the 21st Century. New York: Oxford University Press.

Ma, J. (2011). Ma Jian-Tang explains China's sixth national population census. http:// news.163.com/11/0503/11/734K2LBJ00014JB5.html (May 2011, in Chinese).

National Strategy on Population Development Research Group (2007). The General Report on China's National Strategy on Population Development. Beijing: China Population Publishing House (in Chinese).

NBS (National Bureau of Statistics of China), Department of Population and Employment Statistics (2007 to 2010).China Population and Employment Statistics Yearbook. Beijing: China Statistics Press (in Chinese).

NBS (National Bureau of Statistics of China) (2011a). The Sixth National Census Bulletin No. 1.http://www.stats.gov.cn/tjfx/jdfx/t20110428_402722253.htm (April 2011, in Chinese).

NBS (National Bureau of Statistics of China) (2011b). China Statistical Yearbook. Beijing: China Statistics Press (in Chinese).

NPFPC (National Population and Family Planning Commission) (2008). Population and Family Planning Statistics Handbook. Beijing: China's Population Publishing House (in Chinese).

Qiao, X. (2005). Underreporting of births: The cause of the chaos of the national population statistics in China. Paper presented at the Annual Meeting of the Population Association of America, Philadelphia, March 31-April 2.

Retherford, R.D., Choe, M.K., Chen, J., Li, X., and Cui, H. (2005). How far has fertility in China really declined? Population and Development Review 31(1): 57-84. doi:10.1111/j.1728-4457.2005.00052.x.

Scharping, T. (2005). Chinese fertility trends 1979-2000: A comparative analysis of birth numbers and school data. Population Research 4: 1-15. (in Chinese). 
Sex Ratio at Birth Research Group (2010). Factors Affecting Declining Sex Ratio at Birth in China, unpublished report. Center for Population and Development Studies, People's University of China.

Statistics New Zealand (2011). Net census undercount. http://www2.stats.govt.nz/ domino/external/omni/omni.nsf/wwwglsry/net+census+undercount (July 2011).

UN (United Nations) (2011). World Population Prospects: The 2010 Revision. http://esa.un.org/unpd/wpp/index.htm (May 2011).

Zhang, G. and Zhao, Z. (2006). Reexamining China's fertility puzzle: Data collection and quality over the last two decades. Population and Development Review 32(2): 293-321. doi:10.1111/j.1728-4457.2006.00119.x.

Zhao, Z. (2011). Reflections on China's recent population statistics and current demographic situation. Chinese Cross Currents 8(3): 44-56.

Zhao, Z. and Guo, Z. (2010). China's below replacement fertility: A further exploration. Canadian Studies in Population 37(3-4): 525-562.

Zhao, Z. and Zhang, X. (2010). China's recent fertility decline: Evidence from reconstructed fertility statistics. Population 65(3): 451-478. doi:10.3917/ pope.1003.0451.

Zheng, Z., Cai, Y., Wang, F., and Gu, B. (2009). Below-replacement fertility and childbearing intention in Jiangsu Province, China. Asian Population Studies 5(3): 329-347. doi:10.1080/17441730903351701. 
Zhao \& Chen: China's far below replacement fertility and its long-term impact 